\title{
IMPORTÂNCIA DO PROJETO POLITICO PEDAGÓGICO PARA UMA GESTÃO ESCOLAR DEMOCRÁTICA
}

\author{
IMPORTANCE OF THE POLITICAL PEDAGOGICAL PROJECT FOR DEMOCRATIC \\ SCHOOL MANAGEMENT
}

\author{
Francisco de Assis Amorim de Araújo
}

RESUMO: O objetivo deste trabalho é fazer uma abordagem sobre a importância do Projeto Político Pedagógico, quanto elemento que legitima a gestão democrática da escola. Segue o viés explicativo explique de como acontece a dinâmica do processo de participação na elaboração e aplicação do PPP como instrumento primordial à condução da escola pela equipe gestora, na articulação dos diversos seguimentos inerentes ao processo de ensino e aprendizagem. Trabalho de natureza bibliográfica, fundamentado em autores com larga experiência investigativa sobre a problemática em questão, a abertura a integração das famílias e publicações das ações realizadas pela comunidade escolar à sociedade em geral. Reflexão que se busca ao longo do texto produzido demonstrar que a razão sociopolítica que envolve a escola, contida no seu projeto pedagógico, tem como meta o desenvolvimento de um elevado nível de produtividades acadêmicas dos estudantes, cujos indicadores demonstrem qualidade de aprendizagem. Assim, conclui que a gestão precisa articular na proposta pedagógica um currículo que esteja voltado para as necessidades atuais dos educandos, que insere um modelo de planejamento significativo e participativo. Para garantir um debate permanente e abrangente sobre o currículo, trazendo sempre novos saberes e atitudes às responsabilidades da escolar em si.

Palavras-chave: Escola. Gestão. Participação.

ABSTRACT: The objective of this work is to approach the importance of the Political Pedagogical Project, as an element that legitimizes the democratic management of the school. It follows the explanatory bias explain how the dynamics of the participation process in the elaboration and application of the PPP happens as a primordial instrument for the management of the school by the management team, in the articulation of the different segments inherent to the teaching and learning process. Work of a bibliographic nature, based on authors who have extensive investigative experience on the issue in question, opening up the integration of families and publicizing the actions carried out by the school community to society in general. Reflection that is sought throughout the text produced to demonstrate that the socio-political reason that involves the school, contained in its pedagogical project, has as its goal the development of a high level of academic productivity of students, whose indicators demonstrate quality of learning. Thus, it concludes that management needs to articulate in the pedagogical proposal a curriculum that is geared to the current needs of students, which inserts a meaningful and participatory planning model. To ensure a

\footnotetext{
${ }^{1}$ Licenciado em Filosofia, História e Pedagogia. Especialista em Coordenação Pedagógica e Metodologia do Ensino de Filosofia. Mestre em Educação. Doutorando em Ciência da Educação. Atua como professor na rede pública de ensino da educação básica do Estado do Maranhão e em instituições privadas de ensino superior. Técnico pedagógico na Unidade Regional de Educação de Zé Doca - MA (URE/SEDUC).
} 
permissive and comprehensive debate on the curriculum, always bringing new knowledge and attitudes to the responsibilities of the school itself.

Keywords: School. Management. Participation.

\section{INTRODUÇÃO}

Este trabalho tem o propósito de apresentar uma análise sobre a pertinência do Projeto Político Pedagógico (PPP), no cotidiano escolar, como ferramenta primordial à formulação das ações da gestão escolar, bem como da articulação da práticas pedagógicas. Menciona a importância da gestão democrática, do planejamento participativo e tomadas de decisões democráticas. Configura-se como um trabalho de cunho bibliográfico, cujas fontes consistem em obras de autores experientes que trabalham a temática desde meados do século XX até os dias atuais.

Ressalta que o Projeto Político Pedagógico representa o trabalho da gestão da escola, servindo lhe de refrência de estudo e de trabalho, uma vez que, seu trabalho tem o desafio de traduzir seus conhecimentos em prática pedagógica, em análise da efetivação das práticas metodológicas nas ações docentes. Procura apresentar o sentido da atuação da gestão escolar, na articulação do Projeto Político

Pedagógico da escola, de maneira que o pesquisador se coloca de fora do processo, para ver com isenção o que de fato é relevante, neste aspecto, no cotidiano escolar.

O ponto central da consubstanciação do Projeto Político Pedagógico da escola, atende ao binômio elaboração-execussão, pois desde a mobilização dos agentes da escola até a conclusão são várias etapas, para que ele se torne um instrumento que garante a identidade da escola. É bem interessante o papel político da gestão escolar na articulação entre os seguimentos e a política educacional, a elaboração e reelaboração, implantação, implementação e avaliação a partir da realidade escolar. Outro fator elementar é a observância à legislação educacional, o que exige compreensão da efetivação das práticas escolares, dos fundamentos teóricos da educação e dos procedimentos de transformação das práticas, à medida que se realiza o trabalho educacional, sempre buscando a eficiência e eficácia para se obter resultados positivos.

Participação é a chave do sucesso para a prática escolar democrática. Estando a gestão escolar sempre embasada nos documentos oficiais, dando abertura às discussões nos seguimentos para elaboração do Projeto Político Pedagógico da Escola e assembleia-geral para sua validação. Conclui que, o PPP é um instrumento que harmoniza os interesses individuais como foco na coletividade, no meio escolar, onde todos tem a responsabilidade de construir o melhor que puder neste processo. 


\section{DIMENSÃO SOCIAL E POLÍTICA DA GESTÃO DA ESCOLA}

Iniciamos a abordagem do presente tópico com um premente questionamento: Qual o papel da gestão escolar no sentido político e pedagógico? Basicamente, podemos dizer que o grande papel do gestor escolar é revelar através de sua atuação na escola, o caráter de comprometimento social e político da instituição de ensino, expresso no Projeto Político Pedagógico, para garantir uma formação de excelência aos estudantes. Tratando sobre o sentido do projeto, Gadoti (1994), afirma que o mesmo:

[...] supõe rupturas com o presente e promessas para o futuro. Projetar significa tentar quebrar um estado confortável para arriscar-se, atravessar um período de instabilidade e buscar uma nova estabilidade em função da promessa que cada projeto contém de estado melhor do que o presente. Um projeto educativo pode ser tomado como promessa frente a determinadas rupturas. As promessas tornam visíveis os campos de ação possível, comprometendo seus atores e autores [...]. (GADOTTI, 1994, p. 579).

Tomando esta reflexão no campo educacional, podemos inferir que há uma sueração do simples fato de racionalidade do ato educativo e, que, agora as perspectivas são de total engajamento de todos os entes do processo. Ai está presente a abertura para a formalização de diversos meios de ensino, desde que o foco central seja a emancipação da pessoa em sentido integral. Assim, a gestão escolar atua como elo que direciona os esforços a um olhar indissociável, que é a aprendizagem do estudante, sua formação como pessoa, como sujeito político e social.

Neste sentido a gestão escolar tem um caráter operacional bem definido, que corresponde a capacidade de fazer acontecer, isso é importante, pois significa não ficar no mundo das ideais. Partindo do plajeamento, que se define como objetivos, bem como as ações e os métodos necessários para atingi-los, visando a um processo de escolarização que atenda a todos os alunos. (LIBÂNEO; OLIVEIRA; TOSCHI, 201o, p. 345-346). Com o direcionamento articulando à atribuição de sentido dialético à gestão em princípios éticos, políticos, epistemológicos. Isso implica tanto o domínio, não qualquer, mas baseado num quadro referencial das questões do cotidiano, quando a visão de futuro, sem perder a memória das experiências significativas do passado. A gestão, assim, entendida corresponde também a um processo de aprendizagem.

O PPP de uma escola é um planejamento macro, que é preciso ser feito, considerando a participação de gestores, professores, estudantes, pais e responsáveis, bem como os demais servidores da escola. Deste instrumento serão desdobradas as ações que focam nas mudanças do que precisa mudar, ou em fortalecer as práticas que estão dando resultados satisfatórios. Nas palavras de Veiga 
(2013, p.r6), a escola é promotora de igualdade de oportunidades, ao mesmo tempo, em que ela amplia a quantitativa de ofertas, fará com que o atendimento ao seu público seja a marca da qualidade. Isto é, acesso e permanência do educando com sucesso acadêmico. Pois, a escola deve ser um espaço, que desde o início da incersão do estudante, seu primeiro dia de aula ela vai cativá-lo e motivá-lo, garantindo-lhe meio de chegar aos objetivos pelos quais se busca uma instituição de ensino.

Os gestores da escola devem ter em mente todo o apectro da realidade social que ali se apresenta, fazendo o real diagnóstico das situações, ponderar os considerar os pontos positivos e os desafios, para por meio do planejamento das ações curriculares afirmar a verdadeira identidade da escola. Para tanto, é indispensável a definição de estratégias de acompanhamento e averiguação dos indicadores de resultado da aprendizagem e dos processos de ensino, para mitigar as fragilidades na aprendizagem dos estudantes. E, assim, respaldar o seu progresso e permanência na escolar, uma vez que, o baixo desempenho escolar enseja o elevado grau de abando escolar.

Por esta razão há de existir no escopo pedagógico da escola um conjunto de práticas pedagógicas, que assistam os estudantes diversificadamente no curso de sua aprendizagem. $\mathrm{O}$ que propõe a parte diversificada da BNCC, quando situa as práticas de tutoria, estudo orientado e disciplinas eletivas que auxiliarão na consubstanciação dos conhecimentos do currículo comum, ao estudante. A garantia de uma educação de qualidade não deve ser privilégio das classes sociais economicamente mais elevadas. A educação pública também deve ser sinônimo de qualidade e garantia de emancipação humana e social das pessoas para que no aspecto político sejam capazes de tomar as melhores decisões na coletividade.

De acordo, ainda, com o que ressalta Veiga (2013, p. 17), não pode constar no repertório das ações da escola os termos "reprovação" e "abandono". Pois, se o processo de gestão do ensino e dos conhecimentos for de qualidade, os estudantes terão resultado satisfatório. Logo, o nível de classificação da escola nas avaliações internas e externa será bom e, com isto, as ações defindas por todos e assentadas no PPP, constituem o concepto de escola, sociedade, cidadania e visão de mundo, para obter sucesso e qualificação ao fim que lhe permite existir. E Saviani (1983), ressalta:

Todo projeto pedagógico da escola é, também, um projeto político por estar intimamente articulado ao compromisso sociopolítico com os interesses reais e coletivos da população majoritária. É político, no sentido de compromisso com a formação do cidadão para um tipo de sociedade. A dimensão política se cumpre enquanto ela se realiza enquanto prática especificamente pedagógica. (SAVIANI, 1983, p. 12).

Diante do esposto, entendemos que a escola representa um posicionamento social à medida que ela se propõe a executar um plano de formação, dedicado à sociedade onde ela se estabelece. As 
suas ações pedagógicas correspondem ao processo de ensino-aprendizagem, tendo em foco o que ocorre dentro e fora do espaço das aulas como situação viável de construção de conhecimento. O PPP é um instrumento aglutinador e articulador das diversas ações da escola. O gestor escolar tem que desempenhar o papel de articulador das discussões e decisões coletivas promovendo a troca de informação e conhecimentos, garantindo ações decisórias que fortaleça a escola e esta, se torne a responsável pela construção do indivíduo numa relação de formação, de apropriação de conhecimento, resultando na compreensão de si mesmo, do mundo e das relações que se estabelecem socialmente através da construção histórica e concreta do sujeito.

Neste sentido, o Projeto Político Pedagógico é a própria escola em movimento, a medida que se configura como elemento que oportuniza a discutir coletivamente seus dilemas e as responsabilidades de cada ator ou grupo de atores na busca do alcance de sua função educativa. Neste contexto, configuram-se a gestão e a atuação do gestor escolar, considerados fatores primordiais no desempenho de uma instituição escolar moderna. Para isso falta uma formação para

A gestão escolar. Com as complexidades dos processos sociais, hoje a escola é muito requisitada pela sociedade no seu conjunto e precisa acompanhar as mudanças da vida social.

A escola é um espaço mediador das relações sociais e políticas que objetiva a formação do sujeito em consonância com o desenvolvimento cognitivo e socioafetivo de sua comunidade. Para isso o Gestor deve estar atento às mudanças e se adaptar aos novos paradigmas. Assim, estará apto a acompanhar o desenvolvimento dos alunos e garantir uma formação adequada para os novos tempos.

Em que um Projeto Político Pedagógico só tem efeito quando o Gestor da escola procura coletivamente entender a necessidade da identificação sistemática das dificuldades encontradas no contexto escolar, quando procura definir currículo e metodologia adequadas ao meio e a sua realidade, quando aperfeiçoa as formas de associação e participação dos alunos em processos de solução de problemas e tomadas de decisões; quando promove o envolvimento dos pais na vida da escola; quando estabelece relações interpessoais na escola e quando interfere nas práticas avaliativas como parte integrante do ensino e da aprendizagem, sendo o gestor um elemento integrador $e$ motivador da progressão da aprendizagem. Assim faz sentido a existência do Projeto Político Pedagógico na escola.

A gestão da escola agrega uma complexidade de ações a serem desenvolvidas pelo gestor, que vão determinar a identidade de sua gestão. Assim, especifica-se o estudo voltado para as ações do Projeto Político Pedagógico no que tange o conhecimento trabalhado no pedagógico, no inter- 
relacionamento de seus parceiros e no atendimento de seu ambiente educativo. Direciona-se a responsabilidade do movimento de articulação do Projeto Político Pedagógico para o gestor escolar, porque se acredita que ele tem um papel altamente significativo para proporcionar as condições que favoreçam a autonomia da escola. É o gestor encabeça a viabilidade das ações baseado em valores e justiça, é aquele que enxerga outras possibilidades e cria espaços de sentido, ética, de realização e excelência. Dendo ter uma visão diferente daquelas pessoas que só enxergam a escola como espaço de pressão, estresse e conflitos.

\section{PARTICIPAÇÃO E TOMADA DE DECISÃO CONJUNTA}

Neste tópico queremos fazer uma abordagem a respeito do compartilhamento de responsabilidades no interior da escola. Isto está voltado ao valor da gestão democrática ${ }^{2}$, como principio que franquea a participação coletiva, para as todas de decisões, para o enfrentamento das problemáticas, no intuito de promover avanços significativos, colocando em processo de melhoria continua a estrutura funcional escolar. Desta forma, abre-se um espaço para um diálogo constante a respeito do papel social e político do ente, gestão escolar, tendo a participação coletiva como elemento chave para promoção da gestão democrática. A este respeito Luck (2008) compartilha da ideia que a gestão democrática tem sua legitimação no aporte que os valores da participação coletiva traz à validação das decisões e implementação do planejamento no trabalho cotidiano da escola.

A escola é um elemento da sociedade para a sociedade, onde os conhecimentos construídos ao logo do tempo de existência da humanidade, são trabalhados como fonte saberes com foco no enfrentamento dos desafios da atualidade. Por esta razão as questões do dia a dia devem ser registradas nos instrumentos devidos, para nos momentos de avaliação dos processos a gestão escolar e demais seguimentos ali representados tenham subsídios às novas ações elaboradas. É interessante dizer que quando a escola realiza o planejamento de uma ação, mediante uma situação a ser resolvida ou mitigada no seu âmbito de atuação, não descuidar em definir o passo a passo de sua execução, com datas de início e termino, bem como os responsáveis por cada etapa ou estratégia deste escolpo de trabalho.

\footnotetext{
${ }^{2}$ Os debates a respeito da problemática da Gestão Democrática da escola pública datam do início dos 1980, no século XX, sendo instituída legalmente a partir de sua implementação na Constituição Federal de 1988. E sua concretização, no âmbiro escolar, está regulamentada pelos artigos i4 e is da LDB (Lei n.. 9.394), de 20 de dezembro de 1996.
} 
$\mathrm{Na}$ visão de Luck (2007), cabe a todos que fazem parte do processo educacional escolar, a viabilização do trabalho participativo. Com especial ênfase na atuação do gestor, que tem a incumbência maior de zelar pelo princípio da gestão democrática, para que o trabalho seja implementado mediante a participação da comunidade. Isto implica na alteração do modo de ver e atribuir conceitos dos elementos básicos da gestão, no sentido que trata Araújo (200o), quando destaca o sentido de participação, autonomia, transparência e pluralidade. Tais elementos têm grande relevância, pois são a base da articulação da educação democrática.

É interessante retalharmos alguns elementos acima citados, para eu não paire sobre eles alguma sobre de incompreensão, a saber:

- Participação: A participação deve ser garantida a todos os envolvidos no processo de ensino e aprendizagem. A escola, concebida como uma instituição de responsabilidade de todos professores, pais, agentes educacionais, comunidade e equipe gestora que participam efetivamente nos processos de tomada de decisão -, tem maiores possibilidades de diminuir ou evitar o abandono, a evasão e a repetência de estudantes. Neste sentido, o desafio do diretor consiste em ampliar e criar canais de participação dos sujeitos sociais nos rumos da escola, afirmando-a como espaço público da cidadania.

- Autonomia: de acordo com a visão de Veiga (I998), a autonomia, aponta quatro dimensões, articuladas e relacionadas entre si, consideradas fundamentais para a escola na organização do trabalho educativo. São elas: I. Administrativa: relaciona-se com as questões administrativas, como administração de pessoal e material, controle dos indicadores de desempenho, avaliação do trabalho. 2. Financeira: elaboração de planos e execução dos recursos financeiros adequadamente, observando os fins educativos. 3. Pedagógica: trata especificamente das questões pedagógicas como função social da escola, organização curricular, avaliação, que parte de um amplo processo coletivo. 4. Jurídica: refere-se às normas, às orientações elaboradas pela escola, aos estatutos, ao regimento, aos avisos, às portarias. Essa dimensão possibilita que as ações sejam discutidas e elaboradas coletivamente. A autonomia sobressai à força do aspecto pedagógico com a elaboração do Projeto Político-Pedagógico pelo coletivo escolar e a gestão centrada nos Órgãos Colegiados da escola.

- Transparência: Elemento constitutivo da Gestão Democrática, revela-se no livre acesso à informação. A transparência costuma apresentar-se como um meio eficiente de dar credibilidade ao espaço público, ou seja, a lisura que permite aos cidadãos participarem do controle social. Sendo assim, como todos os envolvidos no cotidiano escolar são chamados a participarem de 
sua gestão, toda e qualquer decisão ou ação tomada, ou implantada na escola tem que ser do conhecimento da coletividade. A transparência na escola depende da inserção da comunidade no cotidiano escolar, do envolvimento dos segmentos com as questões da escola, e passa pela socialização das informações, o que pode gerar um clima de confiança e de clareza de propósitos entre todos os envolvidos no processo educativo.

- Pluralismo: Na opinião de Araújo (200o), é o pluralismo que se consolida como postura de "reconhecimento da existência de diferenças de identidade e de interesses que convivem no interior da escola e que sustentam, através do debate e do conflito de ideias, o próprio processo democrático" (ARAÚJO, 200o, p. 134). Nesse sentido, é imprescindível que haja o respeito às diferenças de pensar e de opiniões para, coletivamente, alcançar os objetivos da escola em relação à formação e aprendizagem dos estudantes.

Estas definições quando bem compreendidas, potencializa-se o estabelcemimento do real sentido da democracia, na prática escolar. Uma vez que, não está associada apenas solucionar os problemas identificados pela gestão da escola, mas envolver a todos na análise dos fatos e no desdobramento das ações mitigadoras das situações conflitantes. Por isso, é indispensável haver um entendimento conjunto do significado social e pedagógico das estratégias apontadas à busca de soluções, que outros encaminhamentos poderiam ser adotados de modo a obter resultados mais significativos. Portanto, sem tais questionamentos, e o compromisso com o encaminhamento de ações transformadoras, para que as decisões tomadas não seja apenas operacional.

$$
\text { Como expõem (OLIVEIRA, MORAES e DOURADO, 2012). }
$$

A idéia básica é a da gestão como um processo de idas e vindas, construído por meio da articulação entre os diferentes atores, que vão tecendo a feição que esse processo vai assumindo. A gestão democrática é a expressão de um aprendizado de participação pautado pelo dissenso, pela convivência e respeito às diferenças em prol do estabelecimento de espaços de discussão e deliberação coletivos. (OLIVEIRA, MORAES e DOURADO, 2012b, p.7).

Isto se faz importante para que haja garantia de abertura à transparência, flexibilidade com fundamentos à gestão participativa. Se não for assim as tomadas de decisão ficam limitadas às questões operacionais. Porém, quando se nevolve todos para discutir e decidir os aspectos negativos tendem a ser dirimidos com maior tenacidade. Diante disto, vale destacar ser importante que o gestor escolar dê publicidade ao Projeto Político Pedagógico da escola. Pois, o PPP é um planejamento multidimensional, dando viabilidade às estratégias e desenvolvimento de ações, que dão vida ao fazer pedagógico. Não é um ato individual, é coletivo. 
No contexto da atuação escolar, o planejamento é um momento político, onde se pensa as ações que as ideias de toda a comunidade e os princípios norteadores gerais, legais da articulação à qualidade da educação. Eis porque o Projeto Político Pedagógico deve ser um instrumento basilar que atenda às necessidades da escola, referenciando o grau de sua responsável pela formação do indivíduo e a formação de sujeitos autônomos, solidários e competentes. Elementos que estão presentes nas Diretrizes Curriculares para a Educação Básica, que focam em conhecimentos e metodologias atuais e condizentes à realidade social.

\section{ADEQUANDO CURRÍCULO E METODOLOGIA À REALIDADE DA ESCOLA}

Aqui, trazemos à reflexão a ideia de que concretização da autonomia do estudante depende em grande parte, se a escola possui um Currículo integrado, que leve em conta os saberes culturais e científicos, conduzidos à problematização das situações presente no âmbito local, da vivência do educando, elevando o grau de complexidade das abordagens até chegar aos problemas globais, cuja pertinência cumprem o proposito do Projeto Político Pedagógico. Nesse sentido deve a gestão escolar compreenda a função de um currículo, pois exige que o professor se aproprie não só dos princípios legais, políticos, filosóficos e pedagógicos que fundamentam o mesmo, mas que seja um mediador do processo ensino-aprendizagem. Esta articulação deve permear o fortalecimento dos laços de solidariedade e de tolerância recíproca, cujo exercício é mediado princípios pedagógicos estruturantes do currículo, cuja base acenta-se sobre os eixos da interdisciplinaridade, contextualização e flexibilidade, trabalhados de forma dialética.

Conforme menciona Ferreira (2011) a denominação currículo refere-se ao conjunto de disciplinas que compõem a estrutura de conhecimentos a serem trabalhos em um curso. Ademais, o currículo escolar a finalidade de fazer um trabalho formativo, através do qual, os consteúdos sejam abordados mediante a relevância da situação histórica, tanto para a escola como para a sociedade. Sobre o sentido do currículo no contexto pedagógico Santos e Paraíso (1996), destacam:

\footnotetext{
Inicialmente significava um arranjo sistemático de matérias, ou um elenco de disciplinas e conteúdos. Posteriormente, o currículo foi entendido como um conjunto de estratégias para preparar o jovem para a vida adulta. Além disso, o currículo também já foi definido como conjunto de experiências trabalhadas pela escola ou conjunto das atividades e dos meios para se alcançarem os fins da educação. (SANTOS; PARAISO, 1996, p.84).
}

Tendo em vista a definição supra citadas, podemos dizer qie é importante que a escola tenha no escopo estruturante de sua atuação social e política, uma perspectiva de valores e missão, de 
caráter inclusivo. O currículo da escola no que tange as diretrizes da LDBEN (Lei de Diretrizes e Base da Educação Nacional), não pode se furtar à promoção das transformações sociais, através da formação das pessoas com saberes bem fundamentados.

O que diz o Art. 26, LDBEN:

Os currículos da educação infantil, do ensino fundamental e do ensino médio devem ter base nacional comum, a ser complementada, em cada sistema de ensino e em cada estabelecimento escolar, por uma parte diversificada, exigida pelas características regionais e locais da sociedade, da cultura, da economia e dos educandos. (BRASIL, 1996). ${ }^{3}$

A diversidade de situações que a escola enfrente e que deve atuar, dão a dimensão dos desafios a serem dimensionados e considerando no processo de ensino. A educação está vinculada ao mundo do trabalho e à prática social, exigindo formação de competências e de habilidades e, ao mesmo, tempo desafia a pessoa continuar aprendendo, seja para o trabalho, quanto para o bom exercício da cidadania. Uma vez que, é indispensável ter autonomia intelectual associada a capacidade crítica, ou seja, saber discernir com exatidão frente a tudo que o envolve. É ter capacidade de compreender os fundamentos científicos e tecnológicos dos processos produtivos e relacionar a teoria com a prática, criar e reinventar meios, caminhos para o progresso.

Isto está intimamente ligado o processo de autonomia da escola, pois a meta do processo de ensino é superação da complexidade de cada área do conhecimento. $O$ que deve culminar num processo de abordagem dialética, que passa pela interação do sujeito aprendiz, que à luz da realidade significa os conhecimentos, elucidando suas lacunas de saber e afirmando-se diante das dicotomias entre si e o mundo. Assim, o educando como sujeito histórico produz sua existência e desempenha suas habilidades e competências, na prática cotidiana. Isto consiste no exercício da consciência, a clareza das ideias, ao ato da reflexão. Assim,

A conscientização implica, pois, que ultrapassemos a esfera espontânea de apreensão da realidade, para chegarmos a uma esfera crítica na qual a realidade se dá como objeto cognoscível e na, qual o homem assume uma posição epistemológica. (FREIRE, 2006, p. 30).

Para Freire sentido dialético da educação, o processo educativo são meios de desvelamento dos mitos pela razão, permitindo à pessoa a capacidade de entender a sua realidade e de agir sobre ela, com consciência clara de si, suas possibilidades de interação

\footnotetext{
${ }^{3}$ Redação dada pela Lei no 12.796, de 2013. Que altera a Lei no 9.394, de 20 de dezembro de 1996, que estabelece as diretrizes e bases da educação nacional, para dispor sobre a formação dos profissionais da educação e dar outras providências.
} 
dialógicas. Compreendendo que a aprendizagem é a construção e reconstrução do conhecimento em seus diversos âmbitos e sentidos, ocorrendo de maneira não arbitrária. E, neste sentido, os procedimentos metodológicos, a efetivação curricular e da aprendizagem deve atender as reais necessidades do estudante, fortalecendo sua estrutura cognitiva.

Considerando a educação com prática do diálogo, o currículo constitui-se como uma construção cultural, um acervo de conhecimento socialmente válido e o reflexo do processo histórico, que une diante da realidade os interesses que vislumbram o saber altivo e proeminente. Ele representa não apenas os interesses sociais, mas as identidades e subjetividades sociais determinadas. Seguindo esta compreensão sobre a finalidade do currículo Santomé (1998), enfatiza:

[...] o currículo pode ser descrito como um projeto educacional planejado e desenvolvido a partir de uma seleção da cultura e das expectativas das quais se deseja que as novas gerações participem, de modo a socializá-las e capacitá-las para ser cidadãos e cidadãs solidários, responsáveis e democráticos. (SANTOMÉ, 1998, p. 95).

Através desta reflexão do autor, fica claro que o processo de elaboração do currículo escolar é, portanto, um processo social, no qual são articulados fatores lógicos, epistemológicos e intelectuais. Neste momento é necessário considerar as múltiplas diferenças no que tange ao conhecimento dos estudantes, considerando manipulação de tecnologias e experiências de vida, bem como valores e atitudes que fazem com que cada um compreenda seu pertencimento ao contexto onde vive. A escola é, portanto, o lugar favorável a aprendizagem e ao protagonismo dos estudantes, por meio da execução das metodologias de aprendizagem, características do processo de ensino.

\section{A MEDIAÇÃO ENTRE A ESCOLA E AS FAMÍLIAS DOS ESTUDANTES}

Analisamos que, o modo como são constituídas as relações entre gestor escolar, estudantes, professor, escolar e comunidade pode-se ter um ambiente bem favorável à formação dos educandos. Pois, no que se refere ao modelo de escola que se quer implementar, hão de está presentes valores, hábitos e saberes que, por sua vez, influenciam no modo de agir destes sujeitos, no modo de pensar e sentir de cada um, e, fundamentalmente, dos educandos. Por esta razão o gestor e demais integrante da comunidade escolar, necessitam atuar fazendo com que ali se estabeleçam relações de qualidade e apresso à aprendizagem dos estudantes. Neste sentido, Penin (2002) destaca: 
Por isso, a importância de todos os profissionais que atuam na escola e principalmente do gestor, é ficarem atentos à qualidade das relações que se estabelecem no espaço escolar. Neste sentido, Penin (2002) destaca:

[...] a escola é espaço de construção de relações que imprimem marcas naqueles que por ali transitam. Se estas relações são permeadas por princípios democráticos respeito ao outro, solidariedade, liberdade - as pessoas crescem no aprendizado e no exercício da democracia, caso o contrário, a escola terá falhado em parte de sua missão. Porque para além da função de socializar o saber sistematizado, a ela cabe ensinar a convivência democrática, o respeito aos direitos e deveres individuais e coletivos. Esta é uma aprendizagem que começa na escola e prossegue ao longo da vida. (PENIN, 2002, p. 33).

Tendo em conta a dimensão da vivência democrática, faz parte das responsabilidades da escola, possuir um canal eficaz de comunicação e interação com as famílias dos estudantes. Há muito se fala da necessidade da participação da família na escola, mas ainda é preciso que aconteça de forma satisfatória, pois a escola em suas diretrizes deve laçar mão de meios que possibilite está participação. E no tocante à participação dos pais e responsáveis na vida da escola, acaba-se por fortalecer os laços de cidadania e corresponsabilidade pelo crescimento acadêmico e pessoal dos estudantes.

É fundamental que haja por parte da escola a preocupação em desenvolver ações, que envolva a participação das famílias, acolhendo-as com atenção e interesse, favorecendo a troca de informações, que são úteis aos cuidados cotidianos para com os estudantes. Os pais ou responsáveis devem conhecer bem a proposta pedagógica da escola, seu modo de trabalho, a sistemática de avaliação, a agenda de cada bimestre, os guias de aprendizagem, participar de palestras e reuniões. Esta tarefa de mediação da escola junto aos pais faz com que o trabalho seja mais coeso, integrado e contextualizado.

A escola não pode ser uma instituição fachada, que trabalha o desenvolvimento dos conhecimentos sem uma utilidade real à comunidade onde está inserida. Não pode simplesmente impor a sua visão aos estudantes e sua família, mas construir em conjunto sua perspectivas de valores e missão educativa. E, neste sentido, é preciso possuir uma proposta de gestão democrática que considere as constantes mudanças, que marcam intensas rupturas contextuais e históricas. Assim, os debates em prol dos fazeres da escola ganha terreno sempre mais fecundo, para fazer brotar novos entendimentos e construir nova visão da realidade presente e traçar novas variáveis ao futuro.

A relação entre escola e família deve está em contante esforço de estreitamento. No entendimento de Libâneo (2013),

a participação é o principal meio de assegurar a gestão democrática, possibilitando o envolvimento de todos os integrantes da escola no processo de tomada de decisão e no funcionamento da organização escolar. A participação proporciona melhor 
conhecimento dos objetivos e das metas da escola, de sua estrutura organizacional e de sua dinâmica, de suas relações com a comunidade, e propicia um clima de trabalho favorável a maior aproximação entre professores, alunos e pais (LIBÂNEO, 2013, p.89).

Isto pressupõe que a participação da comunidade na escola, demanda uma atuação da gestão escola primando pelo fortalecimento do vínculo afetivo, para que a presença da família seja efetiva. Assim, vai sendo provocado em todos os que compõem o corpo escolar, atitudes diferenciadas, no que se refere à construção de melhorias. $O$ ato de ouvir a comunidade e compartilhar responsabilidades, favorece a integração dos processos de ensino e culmina na melhor aprendizagem do estudante. Pois, quando escola e família caminham sempre ombreadas, fica mais fácil entender as fragilidades dos estudantes e potencializar os meios que lhes favoreça crescer.

Vale ressalta que a gestão democrática escolar é uma política pública, consubstanciado pelo sistema escolar, com foco nas metas e desafios do plano educacional, considerando as mudanças no ambiente socioeconômico e político. Diante disto, surge a necessidades de atualização das novas demandas educativas, organização de novos paradigmas e enfrentamento das exigências do mercado em todo o mundo. É em vista destas novas formulações que a escola, através da gestão escolar, passa a ter que abolir a falta de foco do ensino, incorporando à educação a busca da elevação dos indicadores de resultados. Isto é "produto de longa evolução histórica e traz marcas das contradições sociais e dos interesses políticos em jogo na sociedade"(Paro, 2006, p.18). Assim, as políticas educacionais fizeram com que a escolar adquira um caráter empresarial, como um novo paradigma de gestão.

Este novo viés educacional formaliza os padrões do ensino em planos e projetos que articulam amplo espaço abrangência, cuja execução se dá na escola, mas alcança as famílias entre outros seguimentos da sociedade. No âmbito da corresponsabilidade a escola pode fazer diversas parcerias com instituições publicas e privadas, de modo a implementar variados meios e recursos que favoreça um trabalho de excelência, para a qualidade da aprendizagem dos estudantes. Estes atos materializam a meta de formação pessoas autônomas, com capacidade critica, com as competências e habilidades próprias de seu tempo.

Diante desta compreensão de desenvolvimento de ações integradoras entre escola e família, Spodek; Saracho (1998) enfatizam:

O envolvimento dos pais na educação das crianças tem uma justificativa pedagógica e moral, bem como legal [...] Quando os pais iniciam uma parceria com a escola, o trabalho com as crianças pode ir além da sala de aula, e as aprendizagens na escola e em casa possam se complementares mutuamente. (SPODEK; SARACHO, i998, p. 167). 
Diante do exposto pelos autores, compreendemos ser na família que a pessoa encontra espaço para absolver os elementos socio-culturais e históricos da sua realidade e por eles estabelecer o processo de socialização. Situação está que a pessoa apresenta na vivência escolar e que ali passará pelo processo de apreensão e compreensão da realidade. Uma vez que, na escola ele está inserido na busca de mudar os fatores que o impedem de ser um sujeito social bem estabelecido.

\section{CONSIDERAÇÕES FINAIS}

Não é tarefa fácil abordar a temática proposta no título deste trabalho. Contudo, compreendemos ser dever da gestão escolar conduzir o processo de elaboração e validação de um Projeto Político Pedagógico, que subsidie a expressão da identidade do ambiente escolar. É indispensável que tenha competências e habilidades para por na cabeça de todos que atuam na escolar, o sentido de pertencimento que aviva os fazeres de todos, na execução de nova práticas que possibilitem a consecução das metas propostas à comunidade escolar.

Isto tem respaldo na ideia de que a gestão da escola não deve abdicar do princípio da gestão democrática. Que lance mão da descentralização das ações e responsabilidades de cada elemento do corpo escolar, das tomadas de decisões conjuntas. Para que os processos e resultados demonstre a junção dos interesses em objetivos comuns. Desta maneira, todos tem possibilidades de crescerem juntos, podendo avaliar a sistemática dos processos e apontar novos paradigma mediante as mudanças porque passe o ambiente social e escolar.

No envolvimento dos atores sujeito está a clara dimensão que a escola necessita ter sobre a sociedade, a cultura, a economia entre outros fundamentos, para encontrar o sentido de seu planejamento e sistema de avaliação que pretende desenvolver. Tudo isto são condições para a melhoria da qualidade da aprendizagem sistematizada e trabalhada com os estudantes. O que tem que ser feito mediante condições propícias à promoção das relações colaborativas na escola, onde todos estejam integrados ao processo educacional. Pois, a escola não atuará bem se seus membros ou parte deles não vivenciam em sua práxis a sistemática do modelo de escola contido no seu Projeto Político Pedagógico.

Diante disto, concluímos que a gestão escolar como articuladora dos processos de ensino e das práticas da rotina escolar, exerce sua liderança regendo o trabalho pedagógico sempre focada na aprendizagem do estudante. Este orquestramento permite que os procedimentos curriculares sejam executados conforme as previsibilidades do Projeto Político Pedagógico. Por isso algumas habilidades são fundamentais, a flexibilidade é uma delas, refere-se à capacidade de negociar, de 
entender as diversas situações do contexto adotando as soluções que melhor convêm ao grupo e não a si próprio. Isto significa que a autonomia da escola e a formação humana caminham à construção de uma sociedade mais cidadã.

\section{REFERÊNCIAS}

ARAÚJO, Adilson César de. Gestão democrática da educação: a posição dos docentes. Dissertação (Mestrado em Educação) - Faculdade de Educação, Universidade de Brasília (PPGE/Unb).

Brasília, 2000.

BRASIL. Lei de Diretrizes e Bases. Lei no 9.394/96, de 20 de dezembro de 1996.

_. Lei n.은 12.796 , de 2013 .

FERREIRA, Aurélio Buarque de Holanda. Aurélio Júnior; Dicionário escolar da língua portuguesa, Curitiba: Positivo, 20II.

FREIRE, Paulo. Pedagogia da esperança. 13.르 ed. Rio de Janeiro: Paz e Terra, 2006.

GADOTTI, M. Pressupostos do projeto pedagógico. In: CONFERÊNCIA NACIONAL DE EDUCAÇÃO PARA TODOS, r., Anais... Brasília: MEC, 1994.

. Moacir. "Pressupostos do projeto pedagógico". In: MEC, Anais da Conferência Nacional de Educação para Todos. Brasília, 28/8 a 2/9/94.

LIBÂNEO, J. C. Organização e gestão da escola: Teoria e prática. 6. ed. revista e ampliada. São Paulo: Heccus Editora, 2013.

. J. C.; OLIVEIRA, J. F. de; TOSCHI, M. S. Educação escolar: políticas, estrutura e organização. 9. ed. São Paulo: Cortez, 2010.

LÜCK, heloísa. Liderança em gestão escolar. Petrópolis: Vozes, 2008.

Heloisa. Gestão educacional: uma questão paradigmática. Petrópolis: Vozes, 2007.

OliVEIRA, J. F. de; MORAES, K. N. de; DOURADO, L. F. Gestão Escolar Democrática: definições, princípios e mecanismos de implementação. 2012b. Disponível em: http://www.letraviva.net/arquivos/2012/anexo-I-Gestao-escolar-democratica-definicoes,principios-e-mecanismos-de-implementacao.pdf. Acesso em: Janeiro de 2021.

PARO, Vitor Henrique. Perspectiva para reflexão em torno do projeto político pedagógico. In: Escola: espaço do projeto político pedagógico. Campinas, SP: Papirus, 1998. O caráter político e administrativo das práticas cotidianas na escola pública. In: Administração Escolar: introdução crítica. I4.ed. São Paulo: Cortez, 2006. 
PENIN, S.T. de S. Refletindo sobre a função social da escola. In: VIEIRA, S.L. (Org.). Gestão da Escola: desafios a enfrentar. Rio de Janeiro: DP\&A, 2002.

SANTOMÉ, Jurjo Torres. Globalização e interdisciplinaridade: o currículo integrado. Porto Alegre: Artmed, 1998.

SANTOS, Lucíola; PARAÍSO, Marlucy Alves. Dicionário crítico da educação: currículo. Presença Pedagógica, Belo Horizonte. 1996.

SAVIANI, Dermeval. Escola e democracia: Teorias da educação, curvatura da vara, onze teses sobre educação e política. São Paulo, Cortez e Autores Associados, 1983.

SPODEK, Bernard; SARACHO, Olívia N. Ensinando crianças de 3 a 8 anos. Porto Alegre: ArtMed, 1998.

VEIGA, I. P. A. Projeto político pedagógico da escola, uma construção possível. 29 ed. Campinas, SP: Papirus, 2013.

. Ilma Passos Alencastro. (Org.). Projeto Político-Pedagógico da escola: uma construção possível. 7 ed. Campinas, SP: Papirus, 1998. 